\title{
Encontros com signos: possibilidades para pensar a aprendizagem no contexto da educação
}

\author{
Angélica Neuscharank* \\ Universidade Federal de Santa Maria \\ Marilda Oliveira de Oliveira* \\ Universidade Federal de Santa Maria
}

Resumo A escrita deste artigo consiste em um estudo sobre o pensamento filosófico de Gilles Deleuze em torno do conceito de signos, e o que o mesmo dispara a pensar sobre a noção de aprendizagem no contexto da educação. Muitas das conexões teóricas aqui expostas foram fundamentadas nos estudos do livro Proust e os signos (DELEUZE, 2010) e na literatura de Em busca do tempo perdido (PROUST, 2006a; 2006b; 2013). Igualmente relevantes foram as experiências docentes que ocorreram concomitantes à pesquisa fazendo pensar a docência através dos signos produzidos na literatura proustiana e a possibilidade encontrada no método da cartografia. Trata-se de uma pesquisa em educação que foi produzida processualmente nos encontros e situações ao longo do trajeto, e que possibilitou pensar o que seria aprender ao encontrar-se com os signos.

PALAVRAS-CHAVE: Aprendizagem; Signos; Filosofias da diferença. 


\title{
Encounters with signs: possibilities to think learning in the context of Education
}

\begin{abstract}
The writing of this article consists of a study on Gilles Deleuze's philosophical thinking about the concept of sign and what it triggers to think in relation to the notion of learning in the context of Education. Many of the theoretical connections proposedwere based on studies of the book Proust e os signos (Proust and Signs) (DELEUZE, 2010), and on the literature Em busca do tempo perdido (In Search of Lost Time) (PROUST, 2006a; 2006b; 2013). Equally relevant were the teaching experiences that have occurred along with the research and allowed me to think teaching through the signs produced in the Proustian literature and the possibility found in the cartography method. This is a research in Education that was processually produced in the encounters and situations along the way, and it allowed me to think what learning while finding oneself with the signs would be.
\end{abstract}

KEYWORDS: Learning; Signs; Philosophies of difference.

\section{Inventar conceitos, cartografar trajetos, uma filosofia da diferença...}

A questão da invenção é pensada a partir de dois aspectos propostos por Henri Bergson (2005). O primeiro diz respeito a invenção como novidade, da ordem do imprevisível, e o segundo a invenção de problemas e não apenas as soluções de problemas. Uma filosofia da diferença não quer instituir um pensamento anárquico, mas postular a constituição de um sistema que prove que o filósofo não se lança a uma aventura irresponsável, pois se compromete com o conceito, com a invenção do mesmo, “(...) o conceito é o singular, em oposição ao universal vazio, é a intenção contra a monotonia do mesmo. O conceito não recria, ele faz - é da ordem do acontecimento" (VIDAL, 2000, p.479).

Gilles Deleuze, principal referência teórica deste artigo, contou com diversos intercessores para invencionar vários conceitos, muitos deles já estudados ao longo da história da filosofia. Dentre eles Félix Guattari, com quem vai demonstrar, desde a década de sessenta, pelo menos, a preocupação com a noção de signo. No livro Proust e os signos, de 1964, Deleuze propõe um pensamento em torno do signo e do tempo, em Lógica do sentido, de 1969, a conexão se dá entre signo e acontecimento/sentido, num momento posterior, com o livro O Anti- Édipo, de 1972, Deleuze e Guattari estudam a relação signo e história.

Para Deleuze (2010), o conceito de signo não está vinculado à determinações da linguagem, do espaço da semiótica, trata-se de um conceito-teoria dos signos. Tendo isso em vista, o artigo compartilha alguns apontamentos fundamentados na produção conceitual deleuzeana do livro Proust e os signos e na literatura de Em busca do tempo perdido de Marcel Proust, além das experiências docentes da sala de aula, 
que ocorreram concomitantes a esta escrita, na intenção de levantar problematizações e não de encontrar respostas, compartilhar sobre os signos encontrados na docência mais do que representar os sentidos. As experiências escolares não aparecerão narradas, mas compõe com o estudo uma possibilidade para pensar a aprendizagem no contexto da educação.

Assim, a partir do método da cartografia1 alguns apontamentos nos permitiram pensar o que poderia ser um aprender pelo encontro com os signos. Esta proposta metodológica contribuiu para produzir uma pesquisa que não trabalhasse sob o viés da atenção seletiva, estabelecendo muitas relações com a concepção deleuzeana de estar à espreita, pois a atenção cartográfica fez funcionar uma atenção que não se limitasse à identificação de atos que focalizassem o objeto para preparar a representação de suas formas, mas através da detecção de signos e forças circulantes, de pontas do processo em curso. Fez com que a pesquisa pudesse brotar pelo meio, pelo que encontrávamos ao longo do trajeto, pelo tanto que nos afetavam.

\section{Do que tratam os signos?}

Qualquer relação com a realidade, de acordo com Deleuze (2010), seja referente a uma imagem, à natureza, à sanidade, à doença, à subjetividade, a pensamentos, a sentimentos, à política, à sociedade, a uma folha que cai, a um cheiro ou sabor, pode ser tomada como um signo, desde que permita a interpretação como uma ação de significar o signo, atribuir-lhe sentido, isto é, seja capaz de disparar sensações e pensamentos inusitados na natureza em questão. Ainda assim, sentimos a necessidade de perguntar: o que seria um signo na perspectiva deleuzeana, a partir e com o pensamento das filosofias da diferença? Há uma complexidade nesse conceito e no que diz respeito ao pensamento de Deleuze ou, por assim dizer, a ausência de uma única definição totalizante do que seria o signo em tal filosofia. Com efeito, a noção de signo na filosofia de Deleuze é pluralista.

Formam o que podemos chamar de um sistema de signos, constituem uma unidade porque os 'mundos' e 'campos' criados são emitidos por pessoas, por objetos, por matérias; tudo pode ser um signo. Mas também porque são heterogêneos e, dessa forma, o sistema é pluralista porque os signos não são do mesmo tipo nem do mesmo gênero: não são emitidos da mesma forma, não têm o mesmo efeito sobre o intérprete, não têm a mesma relação de sentido.

Assim, Deleuze os dispõe em quatro grupos: signos mundanos, signos amorosos, signos sensíveis e signos artísticos. A mundanidade diz respeito aos signos que surgem nas relações sociais dos personagens da Recherche. Cada meio ou grupo tem seu sistema específico de signos e os seus emissores que criam a consistência dos grupos. "O signo mundano surge como o substituto de uma ação ou de um pensamento, ocupando-lhes o lugar” (DELEUZE, 2010, p.6).

A segunda classificação feita por Deleuze (2010) diz respeito aos signos amorosos, onde se assume que apaixonar-se é individualizar os signos que cada um emite, e tornar-se sensível a esses signos, apreendê-los. Apaixona-se não por um signo 
que a pessoa emite, mas um conjunto de signos, por isso, são como uma multiplicidade de mundos inacessíveis, misteriosos e desconhecidos. Não podemos interpretar os signos de um ser amado sem cair em um mundo que se formara sem nós, que se formara com outras pessoas, onde não somos, de início, senão como os outros objetos (DELEUZE, 2010). Sendo assim, quando o amado emite signos, exprime mundos que não fazemos parte, ou ainda, que não seríamos os preferidos.

Os signos amorosos dizem respeito aos segredos que o amante atribui ao ser amado, como portador de signos. Não nos signos vazios, como os mundanos, mas enganosos. $\mathrm{O}$ engano parece ser a crença numa paixão amorosa pelo outro, quando, em verdade, o segredo do amor está em restituir uma harmonia perdida em nós mesmos, nosso hermafroditismo original. Como, nos encontros intersexuais, essa função originária nunca poderia ser alcançada, o amor é sempre enganoso e produz dor. A potência de diferir encontra sua força maior nos signos amorosos (SORDI, 2009, p. 5-6).

Quando chegamos no terceiro tipo de signos, os sensíveis (formados pelos signos da natureza, que exalam sensibilidades), parece que Deleuze (2010) ensaia uma tipologia viva, que fala destes signos que brincam com o imprevisível, e que experienciam do conceito de memória involuntária2. A estes signos se devem os encontros que nos surpreendem por sensações, por memórias revisitadas, por vapores inexplicáveis.

As madeleines, os campanários, árvores, pedras do calçamento, guardanapo, barulho de colher ou de cano d'água são exemplos de signos sensíveis presentes no livro Em busca do tempo perdido, e fazem com que a alegria seja o princípio do encontro com estes signos. No entanto, seu efeito imediato é a necessidade de um trabalho no pensamento: procurar o sentido do signo, organizar novamente o pensamento para representar o que ele despertou. E por assim dizer, o fracasso diante do retorno a organização, a materialização, pois não há possibilidade de estabelecer uma imagem pelo que o afetou corporalmente, por uma sensação corporal: no final o intérprete compreende que "o sentido material não é nada sem uma essência ideal que ele encarna”(DELEUZE, 2010, p.13).

Por sua vez, o mundo da arte, assim como Deleuze menciona sobre os signos artísticos, é desmaterializado. Para ele, "todos os signos que encontramos na vida ainda são signos materiais e seu sentido, estando sempre em outra coisa, não é inteiramente espiritual” (DELEUZE, 2010, p. 39). Fazem parte destes signos: a música, a pintura e a literatura, e são eles que trazem o tempo redescoberto, um tempo original absoluto que compreende os outros. O autor ainda compara a escritura da Recherche com a obra de arte, pois ela seria uma obra de arte em forma de literatura, a revelação das essências que se expressam na liberdade de suas palavras, tão mais porosas do que as palavras pretendem ser e que se aliam para se confundir umas às outras, mais emitindo signos do que significados acabados. Todos os signos convergem para a arte, todos os aprendizados, pelas mais diversas vias, são inconscientemente da própria arte, pois só por ela que chegamos à essência, isto é, à aprendizagem.

Assim, para Deleuze (2010), é disso que tratam as essências, enquanto última palavra do aprendizado, elas ultrapassam os estados de subjetividade e objetividade, 
são alógicas, constituindo a unidade imaterial e o sentido espiritual do signo, tal qual revelado na obra de arte. Este conceito de essência - que aparece em muitas passagens de Deleuze (2010) para falar dos signos artísticos, encontrada e operada nas perspectivas das filosofias da diferença - não se revela na materialidade e não consiste em uma verdade a ser encontrada ou na imposição de um argumento; ela não remete ao Uno, à busca por uma resposta ou no que está 'implícito', mas trata de uma essência que seria capaz de atuar 'entre' o signo e o sentido, capaz de forçar o pensamento a interpretar.

Quando Deleuze fala a respeito do intérprete e das decepções, ele expõe duas ilusões que colocam a interpretação dos signos em perigo, dificultando o aprendizado: o objetivismo e o subjetivismo. No objetivismo, atribui-se ao objeto os signos de que é portador. O próprio "objeto" traz o segredo do signo que emite e sobre ele nos fixamos, dele nos ocupamos para decifrar o signo. O subjetivismo deposita nas associações subjetivas, no sujeito, as ideias da interpretação dos signos.

\section{O tempo redescoberto...}

A primeira obra que Deleuze faz um movimento de inserir outras fontes como a literatura e o cinema, ainda, procurando operar e conceituar outros modos de exercício de pensamento é em Proust e os signos, onde trabalha com a Recherche de Proust e invenciona todo o sistema de signos. Para o mesmo, o signo pode ser uma forma de produzir o pensamento sob outra perspectiva, pois "o signo transborda o pensar: é força que impele e compele; é o impensado que exige pensar. Signo e pensamento não fazem relação nem acordo: encontro heterogêneo e discordante (...)" (VIDAL, 2000, p.480), pensamento na produção de novos enunciados.

Enquanto materialidade da pesquisa e fazendo parte do referencial teórico, fizemos da leitura da obra de Proust, Em busca do tempo perdido, uma experimentação. Procurando pensar com as palavras e páginas, com os blocos de escrita, já que o autor não apresenta referenciais temporais e espaciais precisos. Nesse exercício, o leitor acaba por estar à deriva dos encontros do personagem principal com os signos que o violentam. Em inúmeros momentos, não é possível identificar se o personagem está adormecido, sonhando, se está recordando, ou se aquela cena está de fato acontecendo, como, por exemplo, em uma das passagens em que o 'eu' adormece e no entanto continua a fazer reflexões. Trata-se portanto, de uma literatura que dispara um outro modo de leitura, não representacional, pois desencadeia fluxos de devires, formas não reconhecíveis e verossímeis da natureza.

O conjunto de escritos de Proust dividido em sete volumes, o último denominado $\mathrm{O}$ tempo redescoberto, apresenta uma narrativa sobre a busca da verdade, do que para o autor não estaria vinculada à inteligência, pois elas explicitariam e repetiriam o que já era sabido. As verdades presentes na Recherche não são produzidas por nós, mas chegam até nós e nos surpreendem, transtornam-nos, deixam-nos estupefatos, produzem 'um sobressalto', um despertar. Um extravio da inteligência organizadora a partir de uma sensação corporal. 
Por isso, ao falar da aprendizagem pelos encontros com os signos, desta ação de interpretar, decifrar, Proust acaba dando nova roupagem à presença do tempo, trazendo-o como um elemento necessário para a produção de sentido. De certo modo, signo e sentido estão sempre em relação com o tempo. Assim como Deleuze (2010) pontua, para cada espécie de signos há uma correlação de tempo, de estrutura e organização, classificadas em duas categorias gerais: o tempo perdido e o tempo redescoberto.

Enquanto tempo perdido fazem parte os signos mundanos e amorosos. Sobre os mundanos, estariam vinculados o sentido de tempo que passa, pois o narrador se perde no vazio da vida social, da vida mundana, em vez de aproveitá-lo. Uma etapa que produz no herói, a partir da vacuidade dos signos mundanos, a passagem do tempo, onde o mesmo aprende sobre a alteração e a mudança. Já sobre os signos amorosos, estes estariam vinculados ao tempo perdido devido os esforços gastos com a compreensão e entendimento do que se ama, do sofrimento mediante o ciúme, do amor como mundanidade e como uma experiência radical. Em razão de o ciúme ser considerado para o filósofo, a verdade do amor, o tempo perdido se configura no seu estado mais puro, já antecipando sua anulação, seu desaparecimento, figurando a ruptura, o fim do amor, um tempo que se perde diante da busca e controle pelo objeto amado.

Quanto a classificação de tempo redescoberto, estariam os signos sensíveis e artísticos. Os sensíveis pertenceriam a esta categoria por tratar de um tempo que se redescobre no cerne de um tempo já "desdobrado", “já desenvolvido". Apesar de antecipar o tempo redescoberto, ainda há a sensação de perda de tempo pela vontade de associar às sensações despertadas pelos signos à um fato, tentar buscar a sua causa.

Como última estrutura temporal, os signos artísticos possibilitariam a descoberta do tempo como "tempo puro", "tempo original absoluto", "tempo primordial", idêntico à eternidade, estado "complicado do tempo" (MACHADO, 2009).

É esse tempo - que o pensamento artístico redescobre ao revelar a essência - que reúne perfeitamente, isto é, sem materialidade ou generalidade, o signo e o sentido. O que a arte nos faz descobrir é o tempo tal como se encontra enrolado na essência, tal como nasce no mundo envolvido da essência, idêntico à eternidade. O extratemporal de Proust é esse tempo no estado de nascimento e o sujeito-artista que o redescobre (MACHADO, 2009, p.205).

A forma do tempo, na obra de Proust, é um tempo sem forma, onde o herói da Recherche não aparece de acordo com uma vida biológica e cronológica - infância, adolescência, fase adulta e velhice - nem se quer havendo separação entre os núcleos de personagens e o que devém dos acontecimentos em cada um deles. Os acontecimentos atravessam as relações, as produções de sensações, e ressoam pelos efeitos dos signos. Sendo assim, tanto nas escritas desta pesquisa quanto nos livros de Proust, os fragmentos da memória aparecem e são utilizados como 'álibis' para escrever sobre a experiência do tempo em seu desenrolar. 


\section{Uma aprendizagem pelos encontros...}

Pensar uma aprendizagem pelos encontros com os signos é talvez pensar os encontros como se fossem a primeira vez, vez da inexperiência, do que não distinguimos e pouco nos importa diferenciar, pois as sensações e conexões nos são mais caras. $\mathrm{O}$ artigo indefinido que antecede a palavra aprendizagem não marca ausência de determinação, mas a singularidade de um encontro que não é particular nem universal. Está em jogo a intensidade de uma aprendizagem que não se produz na generalidade e totalidade, mas numa singularidade no mais elevado grau, uma potência intensiva, uma força viva (KOHAN, 2004).

De que maneira os encontros com os signos podem produzir aprendizagens? Talvez possam nos aproximar desses momentos que fazemos coexistir tempos, locais, situações, desses signos sensíveis que despertam lembranças, que nos tocam sem sabermos sua origem, mas que nos sacodem e incitam a produzir sentidos, vinculados à vida. Porque aprender não difere da vida, depende de movimentos solitários, dos sucessos e fracassos, das alegrias e das tristezas, de conquistas e decepções.

Quem sabe como um estudante pode tornar-se repentinamente 'bom em latim', que signos (amorosos ou até mesmo inconfessáveis) lhe serviriam de aprendizado? Nunca aprendemos alguma coisa nos dicionários que nossos professores e nossos pais nos emprestam. O signo implica em si a heterogeneidade como relação. Nunca se aprende fazendo como alguém, mas fazendo com alguém, que não tem relação de semelhança com o que se aprende. (DELEUZE, 2010, p. 21).

Nossos modelos educativos sempre tiveram uma grande parcela conceitual baseada na tradição ocidental e pensada na matriz platônica, isto é, o aprender entendido como recognição. Afirmava Platão que o conhecimento é uma função da alma racional e, sendo esta alma eterna, ela participa do "mundo das ideias". Por isso, quando a alma encarna em um corpo que nasce, dadas as limitações do material, ela esquece de todas as ideias e é ao longo da vida que a alma vai, aos poucos, 'recordando' daquilo que já sabia. $\mathrm{O}$ aprender constitui, portanto, uma recognição, um voltar a saber algo que já se sabia, podendo ser "acelerado" e aperfeiçoado com o treino, que seria o processo educativo resultante do exercício da filosofia, ou conhecimento das puras ideias (GALLO, 2012).

Outras tantas concepções de educação foram surgindo e permanecendo por determinado tempo, mas a concepção platônica do aprender como recognição se radicou no pensamento educacional e pedagógico. Já em termos contemporâneos, segundo Gallo (2012), a Psicologia Educacional aprofundou nos processos educativos certa teoria de ensino/aprendizagem que procura ligar de forma indissociável estas duas ações: o ensinar e o aprender.

As teorias pedagógicas, de forma geral, centraram-se neste vínculo e dependência, acreditando que só se aprende aquilo que é ensinado, havendo sempre necessidade de alguém que ensine. $\mathrm{O}$ que corrobora este posicionamento é a crença de controle sobre o que, como e quanto alguém aprende. Nesse sentido, o processo educativo 
garantiria certa cientificidade e segurança/controle ao professor sobre como ensinar e, consequentemente, a possibilidade de avaliar o aprendizado de cada estudante.

Assim, podemos encontrar pistas nas observações de Gilles Deleuze para uma "quase-teoria do aprender", que difere da tradição ocidental, centrada na recognição platônica. $\mathrm{O}$ aprender através dos encontros com signos estaria vinculado ao interpretar, e interpretar seria explicar ou explicitar o signo enunciando o sentido, que por sua vez vive enrolado no signo, no que nos força a pensar, e só se pensa quando somos coagidos.

Até aqui, nenhum desvio em relação ao sentido etimológico que vimos acima: se ensinar é 'colocar sinais para que outros possam orientar-se', aprender é encontrar-se com esses sinais. Mas Deleuze tira o acento da emissão dos signos (o ensinar) para colocá-lo no encontro com os signos (o aprender), não importa por quem ou pelo que eles tenham sido emitidos (GALLO, 2012, p.3).

Quando Deleuze desloca a emissão dos signos, do ensinar, e aposta nos encontros, no aprender, não só movimenta nosso olhar do modelo educacional linear ensino/aprendizagem como também atenta para a relação dos signos com quem os interpreta. Segundo Deleuze (2010), o aprender, que diz respeito aos signos, considera não só uma matéria, mas um objeto e um ser, como se emitissem signos a serem interpretados. O próprio aprendiz, assim, torna-se "egiptólogo" dos signos dos quais ele se aproxima.

Em Proust e os Signos, Deleuze (2010) fala sobre o aprendizado como uma dolorosa experiência do mundo, um duplo movimento de decepção e compensação diante da exploração e interpretação dos signos - o que ele chamou de "aprendizado de um homem de letras".

Trata-se da aprendizagem que acontece experimentalmente, como um processo constituído por meio da violência dos signos no percurso de toda a vida. Aprendizado que, neste caso, só encontrará a revelação final, a descoberta do sentido espiritual ou da essência absoluta dos signos na velhice, quando o desejo do verdadeiro e a natureza reta do pensamento forem abandonados e as faculdades, adestradas (HEUSER, 2013, p. 7).

Quando somos tocados pelo signo, pela diferença, temos uma experiência de problematização, de invenção de problemas, a partir daí ocorre a busca de solução e de sentido (KASTRUP, 2001). Ao acaso dos encontros segue-se a necessidade imposta pelo que nos força a pensar, isso porque aprendemos por coação, forçados pelos signos, ao acaso dos encontros. Segundo Deleuze, quando a inteligência intervém na busca de sentido, é sempre depois da ação dos signos, uma vez que a inteligência é um processo de solução de problemas e não de invenção de problemas. A inteligência participa, mas não é por sua participação que a aprendizagem pelos signos se dá. A inteligência atua, tem um papel no processo de aprendizagem, mas ela é acionada, forçada pelo encontro com os signos.

Quando o aprendizado está precedido pela inteligência, acaba por nos conduzir a esclarecer aquilo que já estava claro, mas não nos pertence, porque refere-se ao 
mundo das leis mecânicas, que estabelecem relações entre as coisas dadas como naturais. Ditam leis que definem ordem, uniformizam a percepção. No aprendizado que Deleuze (2010) menciona como indeterminável, sem métodos, não é a inteligência que principia, mas o encontro que força a pensar, o que é criado a partir do signo, e não o reconhecimento do objeto. "Deste encontro é que o aprendiz extrai outras tantas leis, buscando decifrar os mistérios que a sensibilidade apreende no signo. A inteligência vem depois, para explicar seu sentido" (SORDI, 2009, p.8).

Segundo a pedagogia ocidental, no âmbito da recognição o que importa é o saber, que, por sua vez, é entendido como adquirido, algo de que se toma posse. Esse saber é passível de ser verificado, quantificado pelos processos avaliativos que se dedicam a corroborar se um estudante aprendeu ou não. No entanto, atentamos para o que Deleuze nos afirma sobre o saber, quando enfatiza o conceito de aprender - "é tão-somente o intermediário entre não-saber e saber, a passagem viva de um ao outro" (2006, p. 238): é processo, passagem, como acontecimento.

Assim, aprender é encontrar-se com o outro, com a pluralidade dos signos ao relacionarmo-nos, a invenção de problemas que pedem uma resposta que é singular, inovadora, ou que apenas nos faz pensar. Relacionamo-nos com o que põe em evidência a heterogeneidade dos signos, visto que eles não são do mesmo tipo, do mesmo gênero, assim como não são emitidos da mesma forma, não têm o mesmo efeito sobre o intérprete, não têm a mesma relação com o sentido, com as faculdades que os interpretam (MACHADO, 2009). Cada um produz o seu sentido, e isso possibilita dizermos que cada um aprende de uma forma diferente, a seu modo. Em uma mesma sala de aula, haverá tantas maneiras de aprender quanto estudantes houver. Segundo Deleuze, já não se trata mais de um trabalho de recognição, mas de decifração, tal como o do egiptólogo que decifra hieróglifos.

\section{Sobre os sentidos produzidos e que não cessam nesta escri- ta...}

Quando Deleuze nos apresenta a possibilidade de conceber um aprender a partir dos encontros, nos faz pensar em várias concepções que envolvem os processos de aprendizagem, tais como: quem interpreta os signos? Onde e por quem são produzidos? Como os encontros acontecem? Podemos direcionar os encontros e o modo de ser afetado por cada signo? Se não está mais vinculado a uma lógica individualizada do estudante, a uma certa racionalidade, em que circunstâncias se irá aprender?

Sem pretensão de respostas, tais problematizações foram lançadas nesta escrita a fim de produzir pensamentos, isso porque, segundo Deleuze (2010), talvez não seja possível saber como uma pessoa aprende, de qualquer modo como aprenda, poderá ser por intermédio de signos e não pela absorção e memorização de conteúdos pré-estabelecidos. Disso que trata a Recherche de Proust, pensada por Deleuze (2010) a partir da literatura Em busca do tempo perdido, como uma busca inconsciente e involuntária das verdades, do conhecimento, um aprendizado que é dos signos, uma busca não apenas pelos depósitos ou sedimentos da memória, mas pelas séries de decepções descontínuas, por rupturas que fazem o aprendiz se interessar por outras coisas, não previsíveis. 
Permitirmo-nos pensar, ao longo das conexões que fizemos para esta escrita, que os discursos permanecem na superficialidade do significante, isto é, quando não experienciamos os encontros com as coisas como uma possibilidade de aprender algo, mas fizemos do encontro uma busca pelo sentido, da significação como algo contido no signo. No entanto, pensar tais movimentos e construir outras formas para um encontro, é um processo difícil, doloroso, requer de nós uma atenção redobrada, pois colocar-se à espreita das potências de um signo é atentar-se para os acontecimentos de uma vida toda que podem ser despertados em um segundo, para o que se passa nas 'pequenas coisas', em uma brecha no cotidiano, em encontros não planejados.

Os signos, sejam quais forem, nos chegam de surpresa, por todos os lados, sem horário definido. A aprendizagem é um pouco disso, do que acontece sem qualquer pretensão de momento, uma busca pela decifração dos signos mundanos, amorosos, sensíveis e artísticos sem saber como poderão chegar, e se de fato chegarão, pois às vezes os encontros não acontecem.

Gilles Deleuze nos deixa, a cada encontro com seus escritos, faíscas que dão a pensar a aprendizagem- o que seria aprender pelos signos? Talvez nos faça reparar no entendimento do pensamento humano ligado ao exercício lógico e cerebral como algo comum e óbvio, algo, portanto, que intentamos nestes escritos a ser repensado, pois ter esta premissa como uma "verdade" nos faz negar outros modos de se aprender no contexto da escola; faz-nos disciplinar os corpos dos estudantes, ignorar suas vontades e desejos para tornar estes processos homogêneos.

Para as filosofias da diferença, o pensamento precisa ser violentado, acionado, forçado, pois pensar não implica procurar, reconhecer. Sob este aspecto, o pensamento acontece quando não esperamos mais nada, é um ato involuntário, resultado de uma produção ao nos encontrarmos com os signos. Assim como o herói na obra Em busca do tempo perdido: o tempo redescoberto (PROUST, 2013) tropeça, sem querer, em duas pedras irregulares e a felicidade então retorna a ele, como em outras épocas, e o faz investigar os sentidos, as causas profundas, a essência, a verdade daquela experiência. "Porque a verdade necessária nunca é produto de uma boa vontade prévia, mas o resultado de uma violência sobre o pensamento” (DELEUZE, 2010 p.15).

Assim são as relações, através dos encontros com pessoas ou com coisas, que ativamos e mobilizamos em nós um aprendizado, ainda que não tenhamos consciência durante esse processo, pois é "ao final que aquele conjunto de signos passa a fazer sentido; e, pronto, deu-se o aprender, somos capazes de perceber o que aprendemos durante aquele tempo, que nos parecia perdido" (GALLO, 2012, p.3). Dessa forma, a aprendizagem está mais relacionada à errância do que propriamente ao resultado como saber, ao acontecimento do que efetivamente aquilo que se adquire, à lembrança dos encontros do que propriamente das coisas.

\section{Referências}

BERGSON, H. A evolução criadora. São Paulo: Martins Fontes, 2005, 398p.

DELEUZE, G. Diferença e repetição. $2^{\mathrm{a}}$ ed. [Trad. de Luis B. L. Orlandi e Roberto Machado]. Rio de Janeiro: Graal, 2006, 286p. 
DELEUZE, G. Proust e os signos. 2 a ed. [Trad. Antônio Carlos Piquet e Roberto Machado] Rio de Janeiro: Forense Universitária, 2010, 173p.

GAGNEBIN, J. G. Entre sonho e vigília: quem sou eu?. In: PROUST, M. Em busca do tempo perdido, vol. 1. posfácio. No caminho de swann. 2006, p. 539-558.

GALLO, S. As múltiplas dimensões do aprender. In: Anais do Congresso de Educação Básica: aprendizagem e currículo. Florianópolis, 2012. Disponível em: <http://www.pmf.sc.gov. br/arquivos/arquivos/pdf/ 13_02_2012_10.54. 50.a0ac3b8a140676ef8ae0dbf32e662762.pdf.>. Acesso em: 10 de abr. 2015.

HEUSER, E. M. D. A Filosofia da discórdia de Gilles Deleuze e a necessidade de uma educação dos sentidos: para pensar o "momento da sensibilização" no ensino de filosofia. Revista Fermentario. n. 7, vol. 2 (2013). Disponível em: <http://www.fermentario.fhuce.edu.uy/ index. php/fermentario>. Acesso: 08 de nov. 2014.

KASTRUP, V. Aprendizagem, arte e invenção. Psicologia em Estudo, Maringá, n.1, vol.6, p.17-27, jan./jun. 2001.

KOHAN, W. O. (org.). Lugares da infância: filosofia. Rio de Janeiro: DPeA, 2004, 184p.

MACHADO, R. Deleuze, a Arte e a Filosofia. Rio de Janeiro, Zahar, 2009, 340p.

PROUST, M. Em busca do tempo perdido: no caminho de swann, vol. 1, 3a ed. São Paulo: Globo, 2006a, 558p.

PROUST, M. Em busca do tempo perdido: à sombra das raparigas em flor. vol. 2. $3^{\text {a }}$ ed. São Paulo: Globo, 2006b, 669p.

PROUST, M. Em busca do tempo perdido: o tempo redescoberto, vol. 7. 3aed. São Paulo: Globo, 2013, 460p.

SORDI, R. O. Proust - Deleuze: do aprendizado da vida ao aprendizado da arte. Arquivos Brasileiros de Psicologia, n. 3, vol. 61, 2009. Disponível em: <http://pepsic.bvsalud.org/pdf/ arbp/v61n3/v61n3a02.pdf>. Acesso em: 20 de ago. 2014.

VIDAL, E. A. Heterogeneidade Deleuze - Lacan. In: ALLIEZ, Éric. (Org.). Gilles Deleuze: uma vida filosófica. [Trad. Ana Lúcia de Oliveira]. São Paulo: Ed. 34, 2000, p.479-494.

Notas

${ }^{1}$ A cartografia - da forma como utilizei na dissertação e como utilizo nesta escrita - é um conceito cunhado pelos filósofos franceses Gilles Deleuze e Felix Guattari em seu livro Mil Platôs: capitalismo e esquizofrenia (1980), numa tentativa de mapear e acompanhar os múltiplos territórios que compõem a vida e que se entrelaçam aos modos de viver. O conceito, oriundo do campo geográfico, é pensado no campo da filosofia e suas relações com a subjetividade, mostrando-se como dispositivo de observação e fabricação de realidades. Através da cartografia, as realidades passam a serem construídas, e não simplesmente constatadas. Ruptura com a lógica positivista de pesquisa, isso porque, o pesquisador (também chamado de cartógrafo) não é mero observador, neutro e passivo, ele sabe que está interferindo no meio onde cartografa, e sua interferência é vivida e significada.

${ }^{2}$ Enterrada sob diversas camadas de esquecimento e indiferença, a memória involuntária produz uma outra possibilidade de acesso ao passado e a suas riquezas insuspeitadas (GAGNEBIN, 2006). Nos conta um pouco das lembranças dos encontros com os signos e não das coisas em si, e por isso, pode atualizar estes outros tempos. 
* Doutoranda em Educação pela Universidade Federal de Santa Maria (UFSM). Santa Maria, Rio Grande do Sul. Brasil.

** Professora doutora da Universidade Federal de Santa Maria, Santa Maria, Rio Grande do Sul. Brasil.

\section{Correspondência}

Marilda Oliveira de Oliveira - Universidade Federal de Santa Maria. Av. Roraima, 1000 - Prédio 16, Laboratório de Artes Visuais. Bairro: Camobi. CEP: 97105900. Santa Maria, Rio Grande do Sul, Brasil.

E-mail: angelicaneuscharank@yahoo.com.br - oliveira.marilda27@gmail.com

Recebido em 08 de junho de 2016

Aprovado em 28 de novembro de 2016 